\title{
An Analysis of Northern Shaanxi Folk Culture Embodied in Northern Shaanxi Folk Songs
}

\author{
Ai Xirong \\ Foreign Languages Department \\ Yulin University \\ Yulin City, Shaanxi Province, P. R. China \\ Email: 353217985@qq.com
}

\begin{abstract}
Northern Shaanxi folk songs are an important artistic form in the area of Northern Shaanxi Province. Northern Shaanxi folk songs are vivid reflections of local people's life and work. They are not only beautiful in tune, but also contain rich folk culture of Northern Shaanxi. An analysis of Northern Shaanxi folk culture contained in Northern Shaanxi folk songs contributes to an in-depth understanding of Northern Shaanxi folk songs and better promotion and dissemination of Northern Shaanxi folk songs and other folk cultures to the outside.
\end{abstract}

Keywords-Analysis; Classification; Folk Culture; Folk Songs; Northern Shaanxi

\section{INTRODUCTION}

Northern Shaanxi is located in the north of Shaanxi Province and it is the combination belt of Eastern China and Western China and also is the fusion area of prairie, the desert and the Loess Plateau. Historically, Northern Shaanxi has been the intersection between the Han nationality and the minority nationalities. This particular geographic location is advantageous to the cultural exchange between the East and West and is conducive to the integration of nomadic culture and farming culture, thus forming unique culture of Northern Shaanxi.

It can be said that Northern Shaanxi is one of the birthplaces of Chinese nation and Chinese culture. There are many traditional artistic forms in this area, of which Northern Shaanxi folk songs are most famous. Folk song is a form of music through which the working classes have traditionally expressed their emotions and feelings. It is inspired by, and is an integral part of, everyday life of the Chinese working classes and is passed down and elaborated from generation to generation. Likewise, Northern Shaanxi folk songs are vivid reflections of local people's life and work. They are very beautiful in tune. Besides, the lyrics of Northern Shaanxi folk songs are also rich in cultural connotations, containing plenty of the local folk culture. Folk culture is always in company with corresponding folk songs; a certain kind of folk songs is always a reflection of certain folk culture. On the one hand, to better understand Northern Shaanxi folk songs requires examining and acquainting with the folk culture in it. On the other hand, if one hopes to learn about Northern Shaanxi folk culture, he or she can rely on Northern Shaanxi folk songs. It can be said the two are interwoven with each other.

\section{NORTHERN SHAANXI FOLK CULTURE AND ITS CLASSIFICATION}

Through thousands of years' sedimentation, Northern Shaanxi folk culture is rich in its variety and content. Northern Shaanxi folk culture is related to almost all aspects of the life and work of the locals. Northern Shaanxi folk culture is characterized by the unique geographical features and the local lifestyle. Northern Shaanxi folk culture is infused in almost all aspects of the life and production activities of the local people. Northern Shaanxi folk culture can be classified into many categories, of which food culture, drinking culture, clothing culture, wedding culture, festival culture, and material life folk culture are most prominent. All those kinds of Northern folk culture have the characteristics of Northern Shaanxi. For example, Northern Shaanxi food culture has its uniqueness and the produces of Northern Shaanxi like mutton, millet, buckwheat flour, broomcorn, date forming the main ingredients of Northern Shaanxi food culture.

\section{ANALYSIS OF NORTHERN SHAANXI FOLK CULTURE EMBODIED IN NORTHERN SHAANXI FOLK SONGS}

\section{A. Food Culture Embodied in Northern Shaanxi Folk Songs}

Food is the paramount necessity of the people. Therefore, food culture is a very important part of the folk culture of one place and Northern Shaanxi food culture is no exception.

The development of Northern Shaanxi food culture is based on the plentiful local produces such as mutton, millet, buckwheat flour, broomcorn, date. The rich food culture is vividly revealed in Northern Shaanxi folk songs and there are a lot of foods present in Northern Shaanxi folk songs. For example, mutton is a specialty of Northern Shaanxi and it is a special food to entertain guests, so the word mutton appears in many folk songs. There are lyrics like "buckwheat facets with mutton soup, you and me never depart", "with bowls of mutton and pieces of fried millet cakes, how can you say my heart is unkind to you". In the former, the hot feeling between young lovers is expressed because in Northern Shaanxi, buckwheat facets and mutton soup together make a delicacy. In the latter, the strong feeling of a female for her beloved is revealed because in Northern Shaanxi, especially in the past, mutton 
and fried millet cakes are one of the best foods to entertain guests. From the lyrics "eating a bowl of dumplings without a mouthful of soup", we can know of a delicious Northern Shaanxi food dumplings with soup, dumplings served with soup making good company and a delicacy. The lyrics "hot fried millet cakes have been served on the table and boiling millet wine is brought to the relatives to drink" show the two specialties of Northern Shaanxi, hot fried millet cakes and millet wine, which are used by locals to entertain relatives and friends. In the song Calling Brother to Come back soon, there are lyrics "Having cooked qianqian and millet porridge". Qianqian is a traditional Northern Shaanxi food, which is black soya bean that is crushed to the shape of a coin (qian in Chinese). The porridge made from qianqian is very tasty and nutritious and is a favorite of the local people.

\section{B. Drinking Culture Embodied in Northern Shaanxi Folk Songs}

Northern Shaanxi lies in the north of China and it is very cold in winter, so drinking alcohol is a way to resist the cold for the locals. Gradually, drinking becomes a custom of the local people and also a way to entertain guests and celebrate big events. Drinking becomes a way of life of the local people and drinking culture also comes into being. This drinking culture is also demonstrated in Northern Shaanxi folk songs.

There are many songs sung and used to persuade other people or guests to drink. For example, there are lyrics like "This is the last toast for you, and please drink this glass of alcohol, then I'll let you go.", "It's not easy for us two to meet. Would you please accept this glass of alcohol?" Besides, there are also songs to advise people to drink wisely, instead of drinking excessively. There are lyrics: Alcohol is made from millet. It softens people's shoulders first, and then legs. God can not afford to drink too much. Drinking culture not only reflects a living habit of local people in Northern Shaanxi, but also reflects their rough, bold, unconstrained, and hospitable characteristics.

\section{Clothing Culture Embodied in Northern Shaanxi Folk Songs}

Northern Shaanxi is a remote area with a long history and it also has its own clothing culture. Although in today's Northern Shaanxi, the traditional clothing is no longer popular and few locals wear the traditional clothes, the traditional clothing culture is still a cultural treasure and is a reminiscence of the local people's life in the past.

The clothing culture also can be seen in Northern Shaanxi folk songs. The famous lyrics go like this: towel with sheep stomach shape has three stripes of blue. The lyrics just describe a kind of towel of which the surface looks like sheep stomach and used to be worn by adult men around the head. Although most men of Northern Shaanxi no longer wear like this, this image of men in Northern Shaanxi is still in people's mind. There are lyrics: wearing a leather coat with fur outsides. It shows in the past, men in Northern Shaanxi wear the leather coat to keep warm in winter, and this kind of coat is quite unique in that its surface is the fur of the leather.

\section{Wedding Culture Embodied in Northern Shaanxi Folk Songs}

The wedding culture in Northern Shaanxi also has its own characteristics. In the past, the marriage in Northern Shaanxi was mostly arranged by parents and there was always a matchmaker for the marriage. The lyrics "The first month a matchmaker came, the second she's engaged. The third month money paid, the fourth she's taken in" vividly reflect such an old wedding custom. However, with the development of the society, young people have more freedom for their marriage and they can choose their own spouses. There are lyrics such as "the goat and sheep walk separately, I am looking for my own spouse", "the old customs of marriage should be destroyed and the new ones should be established" and "free marriage is not faulty and I am too happy". And there are songs entitled Free Marriage and Marriage by Purchase Not Allowed.

Besides, there are some special wedding ceremonies in Northern Shaanxi. There are lyrics "suona blowing comes and drum beating goes, Leaving (without seeing) my dearest, I was carried into Zhou's". The lyrics describe that people use a music instrument suona to welcome the bride and a wedding sedan chair to carry the bride to the bridegroom's home.

\section{E. Festival Culture Embodied in NorthernShaanxi Folk Songs}

Festival folk culture in Northern Shaanxi is also very colorful; the natives of Northern Shaanxi have their special way to celebrate the festivals. The lyrics "the first month is the beginning of spring and every house is decorated with red lanterns" just describe how people welcome the New Year. For the Pure Brightness Day, a traditional Chinese festival for people to visit their ancestral tombs, there are lyrics to describe it: Pure Brightness comes after Cold Food Festival, cold food only without making a fire, steamed bird-shaped buns and fried corn cookies. And for another traditional Chinese festival, June the Sixth, there are lyrics to describe it: On June the Sixth, steamed buns made of new wheat with stewed mutton. On this day, wheat is mature and cut in and fresh flour is ground to make tasty steamed buns for celebration.

\section{F. Material Life Folk Culture Eembodied in Northern Shaanxi Folk Songs}

Local people in Northern Shaanxi have characteristic lifestyle in accordance with their living environment. For example, people in the Loess Plateau live in special houses called cave dwellings, which are dug out of an earthen hill. People living in them feel cool in summer and warm in winter, so cave dwellings are good for people to live in. The locals also have a special type of bed called kang in Chinese, which is heatable brick or adobe bed. These material life folk cultures are also embodied in Northern Shaanxi folk songs. For example, there are lyrics "the cave dwelling is filled with people", "adobe bed (knag) with cold quilt, the little sister cannot fall asleep". Besides, the windows of cave dwellings are also covered with paper to keep warm and make the house bright. For example, as the lyrics go, "the white window paper stuck with widow flowers". Here, widow flowers are a kind of paper cutting art, which is also a well-known Northern Shaanxi folk art. 


\section{CONCLUSIONS}

This paper has only covered a small part of Northern Shaanxi folk culture embodied in Northern Shaanxi folk songs. Northern Shaanxi folk songs are a valuable traditional cultural treasure and should not be neglected in the modern time. Through digging out the rich cultural connotations in Northern Shaanxi folk songs, Northern Shaanxi folk songs can be accepted and favored by more and more people. Besides, to develop the local cultural industry, it is advisable to make good use of the various local cultural heritages, including Northern Shaanxi folk songs. Through integrating Northern Shaanxi folk songs with unique Northern Shaanxi culture, both of them can be developed further and will play a part in the development of the local cultural industry.

\section{ACKNOWLEDGEMENT}

This study was funded by the Scientific Research Program of Yulin City (No. 2012cxy3-31).

\section{REFERENCES}

[1] http://arts.cultural-china.com/en/96Arts9835.html
[2] Ai Xirong, "On Food Metaphor in Northern Shaanxi Folk Songs," Journal of Changsha Social Work College, vol.19, Sept. 2012, pp. 43-44

[3] Huo Xianggui, A Complete Collection of Folk Songs from Northern Shaanxi. Xi'an: Shaanxi People's Press, 2006.

[4] Xin Xuefeng, "An Examination of Folk Customs in Northern Shaanxi Folk Songs, " Symphony: Journal of Xi'an Conservatory of Music, vol.22, Jan. 2003, pp. 21-26.

[5] Wang Dongfeng and Li Yanmei, "Northern Shaanxi Folk Songs and Northern Shaanxi Folk Customs, " Guangxi Social Sciences, vol.21, Sept. 2005, pp. 132-135.

[6] Cao Hongxing, Northern Shaanxi Folklore. Xi'an: Shaanxi Tourism Press, 2009.

[7] Wang Hongyin, Voice from the Northwest. Beijing: Culture \& Art Publishing House, 2009.

[8] Wang Pei, "On Translation of the Folkways in Northern Shanxi from Aesthetics View," Explorations in Music, vol.29, Dec. 2011, pp. 94-97.

[9] The Contemporary Chinese Dictionary (Chinese-English Edition) Beijing: Foreign Language Teaching and Research Press, 2002.

[10] Hui Yu (eds.), A New Century Chinese-English Dictionary. Beijing: Foreign Language Teaching and Research Press, 2004

[11] Huo Xianggui, Northern Shaanxi Customs and Folk Songs. Xi'an: Shaanxi People's Press, 2014.

[12] Zhang Dongru, "On the Characteristics of Northern Shaanxi Folk Culture," Journal of Baoji University of Arts and Sciences (Social Sciences), vol. 37, Feb. 2015, pp. 82-84. 